\title{
The Evaluation of Bacteremia, Bacterial Spectrum and Their Antibiotic Susceptibility Pattern in Chronic Otitis Media Patients Undergoing Tympanomastoidectomy
}

Original Article

\author{
Mahmood Shishegar, Reza Jahangiri
}

Department of Otorhinolaryngology-Head and Neck Surgeries, Shiraz Medical School, Shiraz University of Medical Sciences, Shiraz, Iran.

\begin{abstract}
Background: Chronic otitis media (COM) endures be an important health problem across the world. Unleashed usage of antibiotics caused development of resistant bacterial strains for infections such as COM as well. Useful antibiotics therapy should be selected according to especially susceptibility pattern of most common local organisms.

Aim: The study was conducted from July 2018 to June 2019 in one referral otolaryngology surgical center in the south of Iran to determine the causative microorganisms, their antibiotic sensitivity pattern and occurrence of bacteremia in chronic otitis media patients undergoing tympanomastoidectomy.

Patients and Methods: This study designed with eighty-seven samples from eighty- seven ears which were obtained from patients who suffer from chronic otitis media. aerobic culturing and antibiotic sensitivity testing were done with standard antibiotic discs using the National Committee for Clinical Laboratory Standards guidelines. Also, venous blood samples were taken before and after the operation for microbiological study. fun Chi-square test, t-test were used for the statistical analysis in this study.

Results: No microorganisms were isolated from the preoperative and post-operative blood cultures. Out of 87 patients, microbiological culture was yielded from 51 specimens (58.6 \%). Staphylococci coagulase negative ( $\mathrm{n}=19$, 37\%) was the most common isolate followed by Staphylococci coagulase positive $(n=12,23 \%)$. Susceptibility pattern of Staphylococci spp. showed that almost $80 \%$ isolates were sensitive to Ciprofloxacin followed by almost $60 \%$ to Co-trimoxazole.

Conclusion: Our results proposed that bacteremia might not happen after tympanomastoidectomy. Continuous investigation of susceptibility pattern can improve the success of treatment process for chronic otitis media.
\end{abstract}

Key Words: Antibiotic susceptibility, bacteremia, bacterial isolates, chronic otitis media

Received: 25 June 2020, Accepted: 21 August 2020

Corresponding Author: Reza Jahangiri, MD, Department of Otorhinolaryngology-Head and Neck Surgeries, Shiraz Medical School, Shiraz University of Medical Sciences, Shiraz, Iran, Tel.: 987136291471, E-mail: Rjahangiri62@gmail.com

ISSN: 2090-0740, 2021 Vol.22

\section{INTRODUCTION}

Chronic otitis media (COM) endures be an important health problem across the world. COM is defined as chronic inflammation of the middle ear and mastoid cavity that may together with the perforation of and the discharge from the tympanic membrane ${ }^{[1]}$. Many studies have presented that Pseudomonas sp., Staphylococcus aureus, Klebsiella Pneumonia and Proteus sp. are the common organisms isolated from cases of chronic suppurative otitis media $(\mathrm{CSOM})^{[2]}$. Furthermore, in the patients who have experienced tympanomastoidectomy has been reported to occur bacteremia after surgery that may lead to intense outcomes $^{[3]}$.

In recent years, although widespread use of antibiotics caused an impressive reduction in the public health hazard from infectious diseases, however, this unleashed usage resulted in the development of resistant bacterial strains for other infections such as COM as well ${ }^{[4]}$. Furthermore, the widespread use of antibiotics as prophylactic manner that may administered for 57- days after surgery is another main problem ${ }^{[3]}$. There is no agreement regarding the use of prophylactic antibiotics for ear surgery ${ }^{[5,6]}$.

Useful antibiotics therapy should be selected according to its efficacy, safety, risk of toxicity, cost and especially susceptibility pattern of most common local organisms ${ }^{[7]}$. Therefore, knowledge of the pattern of local antibiogram is very essential for treatment of COM patients.

Basis of our knowledge, for detection of the pattern of local antibiogram, very few the literatures that have been conducted in most parts of our country. Therefore, the main objectives of this study were to address the determine the local pattern of microorganisms involved and their antibiotic susceptibility pattern and occurrence of bacteremia after tympanomastoidectomy in COM 
patients undergoing this surgery referred to one of biggest otolaryngology surgical center in southern of Iran and provide a guideline for experimental antibiotic therapy. Furthermore, the present study aimed to compare studies conducted within Iran as well as the neighboring countries.

\section{PATIENTS AND METHODS:}

87 patients recruited in the study were diagnosed to have COM and scheduled for tympanomastoidectomy whose age ranged from 4 to 58 Years (mean age: 35.3 years). The patients were admitted to our Hospital from July 2018 to June 2019. 41 (47.1\%) of them were male and $46(52.9 \%)$ female. Ethical committee approval was obtained before starting the study. The patients' indications for were suffering from recurrent chronic otitis media and not having received antibiotics for the last 2 weeks.

A microscopic examination was performed to identify any discharge, perforation, polyps, cholesteatoma, granula-tion tissue, and changes in middle ear mucosa. The patients with acute episode of respiratory infection, immune deficiencies or systemic diseases and who had received antibiotics for any reason in the 4 weeks before the operation were excluded from the study.

The patients divided in three groups, including patients with tympanic membrane perforations with dry and wet middle ear, and patients with cholesteatoma. Isolated microorganisms obtained from middle ear and if mastoid was opened, sample was taken from mastoid cavity if needed and put in ammonium thioglycollate culture media. Then, all the samples were transported to the laboratory as soon as possible and the specimens for culturing the aerobic microorganism.

All the procedures were performed under general anesthesia with endotracheal intubation which was maintained by inhalation anesthesia. Tympanomastoidectomy was done by dissection routine method with retroauricular incision. All of the patients underwent tympanomastoidectomy with the same surgical instruments and we used temporal fascia as the source of the graft. The underlay technique was used in all of the cases. In this study, $5 \mathrm{~mL}$ venous blood samples were taken 5 min before and post operation after suturing the skin incision were transmitted to tryptic soy broth (TSB) culture media. Blood culture samples were monitored for 5 days in the biphasic blood culture system. After 24 hours of incubation, Blood culture vials which tested positive with gram stained and microscopically investigation and passaged on sabouraud-dextrose agar and eosin methylene blue (EMB) agar media with sheep blood and incubated at $35^{\circ} \mathrm{C}$ under aerobic conditions. At the end of 5 days, the blood culture vials considered to be negative were passaged on blood agar and evaluated for false negativity. Isolated microorganisms were identified with the BD Phoenix (BD
Diagnostic Systems, USA) fully automated identification system. Gram positive and gram-negative bacterial sensitivity of isolates to commonly used antimicrobials (Gentamicin, Ciprofloxacin, Sulfamethoxazole/ trimethoprim (Co-trimoxazole), Cephalothin, Cefixime, Cephalexin, Erythromycin and Amikacin) were investigated by disk diffusion method using the National Committee for Clinical Laboratory Standards (NCCLS) guidelines $^{[8]}$.

\section{STATISTICAL ANALYSIS}

Fischer's exact test was used to compare the gender between groups. Gender was presented as count and percent-age. The two independent sample t-test was used to compare continuous variables. SPSS 16.0 Windows software (Chicago, IL, USA) was used for all statistical analysis. Results with a calculated $P$ value of $<0.05$ were considered statistically significant.

\section{RESULTS:}

In the present study, middle ear was dry in 35 (40.2\%) patients and $29(33.3 \%)$ of them have granulation tissue, wet ear and $23(26.5 \%)$ cases have cholesteatoma in middle ear and mastoid cavity.

No microorganisms were isolated from the preoperative and post-operative blood cultures. The growth of microorganisms from the samples of dry, granulation tissue,wet ear and cholesteatoma ear were positive in $13(37.1 \%), 18$ $(62.1 \%)$ and $20(87.0 \%)$ patients, respectively.

In conclusion, ammonium thioglycolate culture media was positive in $51(58.6 \%)$ patients. Nevertheless, the posi-tive cultures were significantly more in ears with wet and granulation tissue and cholesteatoma groups compared to cases with dry middle ear $(p<0.05)$.

In addition, our study results showed that a total of 51 samples isolated from three group of patients, staphylococci coagulase negative in 19 cases $(37 \%)$ followed by Staphylococci coagulase positive in 12 cases $(23 \%)$ was the most common isolated organism. (Table 1$)$ presents the frequency of the isolated organism from the patients.

\section{Antibiotic sensitivity tests:}

Staphylococci coagulase negative isolated from patients showed $78.9 \%$ sensitivity to Ciprofloxacin, and high sensi-tivity to Co-trimoxazole $(66.7 \%)$. In contrast, this strain showed no or low sensitivity to Cefixime, Cephalexin, Erythromycin and Amikacin.

Staphylococci coagulase positive showed $83.3 \%$ sensitivity to Ciprofloxacin and low sensitivity to 
Gentamicin, Cefixime, Cephalexin, Cephalothin, Erythromycin and Amikacin. Also, Proteus showed high sensitivity to Ciprof-loxacin (100\%). Streptococcus showed $75 \%$ sensitivity to Ciprofloxacin and Co-trimoxazole. Seratia, Enterobacter and Pseudomonas showed 100\% sensitivity to Gentamicin but showed less than $70 \%$ sensitivity to other antibiotics. Nevertheless, Enterobacter showed $80 \%$ sensitivity to Ciprofloxacin. In conclusion, all the bacteria showed high sensitivity to Ciprofloxacin (76.5\%), Co-trimoxazole (59.6\%) and Gentamicin (50\%) (Table 2).

Table 1: The frequency of the isolated organism from the patients

\begin{tabular}{llll}
\hline & & Frequency & Percent \\
\hline Bacterial species & Proteus & 5 & 10 \\
& Seratia & 3 & 6 \\
& Staph.coa.negative & 19 & 37 \\
& Enterobacter & 5 & 10 \\
Ecoli & 1 & 2 \\
Staph.coa.positive & 12 & 23 \\
& Pseudomonas & 2 & 4 \\
Total & Streptococcus & 4 & 8 \\
& & 51 & 100 \\
\hline
\end{tabular}

Table 2: Antibiotic sensitivity tests of the isolated organism from the patients

\begin{tabular}{|c|c|c|c|c|c|c|c|c|c|}
\hline $\begin{array}{c}\text { Bacterial } \\
\text { Species }\end{array}$ & $\begin{array}{l}\text { No. of } \\
\text { isolates }\end{array}$ & $\begin{array}{c}\text { Gen- } \\
\text { tamicin } \\
\text { No. }(\%)\end{array}$ & $\begin{array}{l}\text { Ciprof- } \\
\text { loxacin } \\
\text { No. }(\%)\end{array}$ & $\begin{array}{l}\text { Co-trimox- } \\
\text { azole No. } \\
(\%)\end{array}$ & $\begin{array}{c}\text { Cefix-ime } \\
\text { No. }(\%)\end{array}$ & $\begin{array}{c}\text { Cephalexin } \\
\text { No. }(\%)\end{array}$ & $\begin{array}{l}\text { Cepha- } \\
\text { lothin } \\
\text { No. }(\%)\end{array}$ & $\begin{array}{c}\text { Erythro- } \\
\text { mycin } \\
\text { No. }(\%)\end{array}$ & $\begin{array}{c}\text { Amika-cin } \\
\text { No. }(\%)\end{array}$ \\
\hline Proteus & 5 & $3(60)$ & $3(100)$ & $3(50)$ & $1(33.3)$ & $1(20)$ & $0(0)$ & $0(0)$ & - \\
\hline Seratia & 3 & $3(100)$ & $2(66.7$ & $1(33.3)$ & - & $0(0)$ & $0(0)$ & $1(33.3)$ & $1(33.3)$ \\
\hline $\begin{array}{l}\text { Staph.coa. } \\
\text { negative }\end{array}$ & 19 & $11(57.9)$ & $15(78.9)$ & $12(66.7)$ & $0(0)$ & $1(5.2)$ & $8(42.1)$ & $2(10.5)$ & $2(10.5)$ \\
\hline $\begin{array}{l}\text { Enterobac- } \\
\text { ter }\end{array}$ & 5 & $5(100)$ & $4(80)$ & $3(60$ & $2(40)$ & $0(0)$ & $0(0)$ & $0(0)$ & $2(40)$ \\
\hline Ecoli & 1 & $0(0)$ & $0(0)$ & - & $0(0)$ & - & - & $0(0)$ & $1(100)$ \\
\hline $\begin{array}{l}\text { Staph.coa. } \\
\text { positive }\end{array}$ & 12 & $2(16.7)$ & $10(83.3)$ & $7(58.3)$ & $0(0)$ & $2(16.6)$ & $3(25)$ & $2(18.2)$ & $0(0)$ \\
\hline $\begin{array}{l}\text { Pseudomo- } \\
\text { nas }\end{array}$ & 2 & $2(100)$ & $0(0)$ & $0(0)$ & $0(0)$ & $0(0)$ & $0(0)$ & $0(0)$ & $1(50)$ \\
\hline $\begin{array}{l}\text { Streptococ- } \\
\quad \text { cus }\end{array}$ & 4 & $0(0)$ & $3(75)$ & $3(75)$ & $1(25)$ & - & $0(0)$ & $1(25)$ & $0(0)$ \\
\hline Total & 51 & $25(50)$ & $39(76.5)$ & $28(55)$ & $4(8)$ & $4(8)$ & $11(21.5)$ & $6(12)$ & $7(14)$ \\
\hline
\end{tabular}

\section{DISCUSSION}

Results of COM surgery, with or without cholesteatoma, is accepted clean-contaminated method [9]. Bacteremia has been reported to as an important postoperative complication after tonsillectomy, septoplasty, septorhinoplasty and mastoidectomy procedures $^{[3,10]}$.

During tympanomastoidectomy, the wound surfaces remain open during the operation allowing bacteremia intraoperatively or postoperatively ${ }^{[10]}$.

In the study by Keleş et al. ${ }^{[3]}$ reported that 5 $(8.5 \%)$ patients of 59 cases developed bacteremia after tympanoplasty procedures with mastoidectomy. In another study, blood cultures were positive for $7(12.3 \%)$ out of 57 patients who underwent tympanomastoidectomy ${ }^{[11]}$. Although, the findings of the current study didn't show bacteremia after tympanomastoidectomy.

A possible explanation for this discrepancy might be that the risks of postoperative infections are related to duration of operations especially in cases with operation duration of more than 2 hours ${ }^{[5]}$.

Postoperative infection incidence of COM surgery was reported as $10 \%$ by American National Research 
Council $^{[5]}$. In COM without cholesteatoma, the most common isolated microorganisms are Pseudomonas aeruginosa and Staphylococci species ${ }^{[11]}$.

Pseudomonas aeruginosa and Staphylococcus aureus revealed as the most common causative organism in different cities of Pakistan ${ }^{[12]}$. The several studies in India revealed that Staphylococcus aureus followed by Pseudomonas species as the most common $\operatorname{organism}^{[2,13]}$.

In the study by Nikakhlagh et al. ${ }^{[14]}$ in Iranian patients with CSOM reported that Staphylococcus aureus followed by Pseudomonas aeruginosa as the most isolated bacteria. In another study in Iran, Kalantar et $a l .{ }^{[15]}$ isolated Staphylococci coagulase negative, Staphylococcus aureus and Streptococcus pneumonia in both the external ear canal of cancer patients and non-hospitalized cancer patients, similarly.

In the present study Staphylococci coagulase negative and Staphylococci coagulase positive were the most common organism and are consistent with other studies. Nevertheless, in contrast to the most of studies Pseudomonas spp. was the lowest organism that isolated from the patients. This inconsistency is not clear but may be due to antimicrobial profiles varies among individuals and zones of the world.

On the other hand, Streptococcus, Proteus and Enterobacter and Escherichia coli were isolated in some our COM patients which are comparable to the findings of other studies ${ }^{[16-18]}$. Overall Staphylococcus aureus and Pseudo-monas aeruginosa were the main etiological agents of CSOM patients that reported from various parts of the world ${ }^{[19]}$.

Antibiotics are used in surgeries with prophylactic goals. Although, the American National Research Council rec-ommended prophylactic antibiotic use no longer than 24 hours $^{[6]}$. The use of prophylactic antibiotics for ear sur-geries haven't acceptable guidelines and patients who undergone ear surgeries used 5-7 days from antibiotics after surgeries ${ }^{[5,6]}$. This overuse of antibiotics can cause the growing prevalence of resistant bacteria, as well as the alteration of antibiotic sensitivity and also indicates the necessity for continuous and periodic bacteriological surveys ${ }^{[20]}$. Finally, a success antibiotic therapy is associated to the understanding of the local susceptibility pattern of microorganisms in each area of world.

Sattar et al. ${ }^{[12]}$ reported $92 \%$ and $85 \%$ antimicrobial sensitivity for Staphylococcus aureus with Moxifloxacin and Ciprofloxacin, respectively.

In the study in India by Prakash et al. ${ }^{[2]}$ Staphylococcus aureus showed high sensitivity to Amikacin, Chloram-phenicol and Piperacillin.
In the study in Kerman, Iran Staphylococci coagulase positive showed high sensitivity rates to Gentamicin (95.5\%), Cephalexin (90.9\%) and Ciprofloxacin $(85.4 \%)$ and they also presented the sensitivity of Staphylococci coagulase negative were in ranged of $27.2 \%$ for Cefixime to $57.1 \%$ for Cloxacillin and Cephalexin.

In the present study Staphylococci coagulase negative and positive showed were highly susceptible to Ciprofloxacin. In agreement with our results Staphylococci spp. sensitivity reported by other studies that presented high sensitivity rate for Staphylococci spp. to Fluoroquinolones such as Ofloxacin and Ciprofloxacin $^{[16,17,21]}$.

Our findings are in agreement with the results of Gul et $a l .{ }^{[22]}$ and Mozafari Nia et al..$^{[17]}$ that Pseudomonas spp. showed high sensitivity to Gentamicin. Similarly, in the study by Maji et al. ${ }^{[23]}$ the most effective antibiotics were Amikacin and Gentamicin in both Pseudomonas species and Staphylococcus aureus.

Moreover, our findings revealed that most of the isolates were found to be susceptible to Ciprofloxacin followed by Co-trimoxazole.

In the study by Kalantar et al..$^{[15]}$ revealed that Staphylococcus Coagulase negative and Staphylococcus aureus were highly resistant to Penicillin G.

The sensitivity pattern of Staphylococcus aureus with commonly used antibiotics such as Ampicillin, Cefixime, Cephalexin are less than $50 \%{ }^{[19]}$. As well our results showed that Staphylococci spp. were highly resistant to Cefixime, Cephalexin and Amikacin.

Clinical resistance of Staphylococci spp. to some commonly used antimicrobial agents such as Penicillin and Cefix-ime is now a problem all over the world $^{[15,17]}$.

Almost $90 \%$ of the organisms in our study showed resistance to Cefixime and Cephalexin. In the next degree, al-most $85 \%$ of the organisms displayed resistance to Amikacin and Erythromycin.

\section{CONCLUSION}

In conclusion the present study performed on 87 patients with COM at referral Iranian hospital showed that Staphylococci coagulase negative was the most frequently detected bacteria, followed by staphylococci coagulase positive. Most of the isolates were found to be susceptible to Ciprofloxacin followed by Co-trimoxazole. Moreover, antibiotic sensitivity 
against the microorganisms was showed to have changed over time. Therefore, bacteriological researches and routine antibiotic susceptibility testing can improve the success of treatment process for COM.

\section{CONFLICT OF INTEREST}

There are no conflicts of interest.

\section{REFERENCES}

1. Da Costa SS, Paparella MM, Schachern PA, Yoon TH, Kimberley BP. Temporal bone histopathology in chronically infected ears with intact and perforated tympanic membranes. Laryngoscope. 1992;102(11):1229-36.

2. Prakash M, Lakshmi K, Anuradha S, Swathi G. Bacteriological profile and their antibiotic susceptibility pattern of cases of chronic suppurative otitis media. Asian Journal of Pharmaceutical and Clinical Research. 2013; 6(3):210-2.

3. Keleş E, Kizirgil A, Kaygusuz I, Karlidağ T, Yalçin Ş, Alpay HC, et al. Bacteriemia during mastoidectomy and/or tympanoplasty. Otolaryngology-Head and Neck Surgery. 2005;133(3):347-51.

4. Osma U, Cureoglu S, Hosoglu S. The complications of chronic otitis media: report of 93 cases. Journal of Laryngology \& Otology. 2000;114(02):97-100.

5. Govaerts PJ, Raemaekers J, Verlinden A, Kalai M, Somers T, Offeciers FE. Use of antibiotic prophylaxis in ear surgery. The Laryngoscope. 1998;108(1):10710.

6. Page CP, Bohnen JM, Fletcher JR, McManus AT, Solomkin JS, Wittmann DH. Antimicrobial prophylaxis for surgical wounds: guidelines for clinical care. Archives of Surgery. 1993;128(1):79-88.

7. Indudharan R, Haq JA, Aiyar S. Antibiotics in chronic suppurative otitis media: a bacteriologic study. An-nals of Otology, Rhinology \& Laryngology. 1999; 108(5):440-5.

8. Zapantis A, Lacy MK, Horvat RT, Grauer D, Barnes BJ, O'Neal B, et al. Nationwide antibiogram analysis using NCCLS M39-A guidelines. Journal of clinical microbiology. 2005;43(6):2629-34.

9. Jackson CG. Antimicrobial prophylaxis in ear surgery. The Laryngoscope. 1988;98(10):1116-23.

10. Kaygusuz Ir, Gök Ü, Yalçin Ş, Keleş E, Kizirgil A, Demirbağ E. Bacteremia during tonsillectomy. Interna- tional journal of pediatric otorhinolaryngology. 2001;58(1):69-73.

11. Uysal İ, Polat K, Uysal E, Koç S. The Comparison of Bacteremia and Amount of Bleeding During Tympanomastoidectomy. Otolaryngology. 2014;4(153):2.

12. Sattar A, Alamgir A, Hussain Z, Sarfraz S, Nasir J Bacterial spectrum and their sensitivity pattern in pa-tients of chronic suppurative otitis media. Journal of the College of Physicians and Surgeons-Pakistan: JCPSP. 2012;22(2):128-9.

13. Kuchhal V. Antibiotic sensitivity pattern in chronic suppurative otitis media in kumoun region. Indian Journal of Otology. 2010;16:17-21.

14. Nikakhlagh S, Khosravi AD, Fazlipour A, Safarzadeh M, Rashidi N. Microbiologic Findings in Patients with Chronic. Journal of Medical Sciences. 2008;8(5): 503-6.

15. Kalantar E, Mosaei M, Ekrami A, Pedram M. Isolation and antimicrobial susceptibility of bacteria from external ear canal of cancer patients at Shafa Cancer Hospital-Ahwaz. Journal of cancer research and therapeutics. 2006;2(1):17.

16. de Miguel MI, Del Rosario QC, Bolaños RM, Ramos MA. Aetiology and therapeutic considerations in chronic otitis media. Analysis of a 5 year period. Acta otorrinolaringologica espanola. 2005;56(10):459-62.

17. Nia KM, Sepehri G, Khatmi H, Shakibaie M. Isolation and antimicrobial susceptibility of bacteria from chronic suppurative otitis media patients in Kerman, Iran. Iranian Red Crescent Medical Journal. 2011;13(12):891.

18. Saini S, Gupta N, Sachdeva O. Bacteriological study of paediatric and adult chronic suppurative otitis media. Indian journal of pathology \& microbiology. 2005;48(3):413-6.

19. Ahmed K, Mir A, Jan M, Imran R, Shah G, Latif A. Prevalence of bacteria in Chronic Suppurative Otitis Media patients and their sensitivity patterns against various antibiotics in human population of Gilgit Pakistan Journal of Zoology. 2013;45(6):1647-53.

20. Yeo SG, Park DC, Hong SM, Cha CI, Kim MG. Bacteriology of chronic suppurative otitis media-a multi-center study. Acta oto-laryngologica. 2007;127(10):1062-7.

21. Macfadyen CA, Acuin JM, Gamble CL. Systemic antibiotics versus topical treatments for chronically 
dis-charging ears with underlying eardrum perforations. Cochrane Database System Review. 2006;25(1):CD005608.

22. Gül H, Kurnaz A, Turhan V, Oncül O, Pahsa A. Microorganisms isolated from middle ear cultures and their antibacterial susceptibility in patients with chronic suppurative otitis media. Kulak burun bogaz ihtisas dergisi: $\mathrm{KBB}=$ Journal of ear, nose, and throat. 2005;16(4):164-8.
23. Maji P, Chatterjee T, Chatterjee S, Chakrabarty J, Mukhopadhyay B. The investigation of bacteriology of chronic suppurative otitis media in patients attending a tertiary care hospital with special emphasis on seasonal variation. Indian Journal of otolaryngology and Head \& Neck surgery. 2007;59(2):128-31. 